Romanian Society of Neurogastroenterology

\title{
Recent Data on Irritable Bowel Syndrome from some Central and East European Countries
}

\author{
Dan L. Dumitrascu ${ }^{1}$, Alexandru Babin ${ }^{2}$, Dmitry Bordin ${ }^{3}$, Jozsef Czimmer ${ }^{4}$, Andriy Dorofeyev ${ }^{5}$, Adelina Galica ${ }^{6}$, Goran \\ Hauser $^{7}$, Snezana Lukic ${ }^{8}$, Agata Mulak ${ }^{9}$, Radislav Nakov ${ }^{10}$, Myrzabey Rustamov ${ }^{11}$, Meri Trajkovska ${ }^{12}$, Vasile L. Drug ${ }^{13}$
}

1) Dept. of Internal Medicine, Iuliu Hatieganu Univ. of Medicine and Pharmacy Cluj-Napoca, Romnia; 2) State Medical and Pharmaceutical Univ. Nicolae Testemițanu,

Kishinew R. Moldova; 3) A. S.

Loginov Moscow clinical scientific center, Moscow, Russia; Tver State Medical Univ., Tver, Russia; A.I. Yevdokimov Moscow State University of Medicine and Dentistry, Moscow; 4) Div. Gastroenterol, First Dept. Medicine, Medical School, Pecs Univ., Pecs, Hungary; 5) Nat. Med. Academy of Postgraduate Education n.a.P.L.Shupik, Kyiv,Ukraine; 6) School of Medicine, Univ. Fan S. Noli, Korce, Albania; 7) Dept. of Gastroenterol, Clin. Hospital Centre Rijeka, Med. Faculty Rijeka; Faculty of Health Studies, Rijeka, Univ. of Rijeka, Rijeka, Croatia; 8) Gastroenterol and Hepatol Clin., Clinical Centre of Serbia, Faculty of Medicine, Univ. of Belgrade, Serbia; 9) Dept. of Gastroenterol and Hepatol, Wroclaw Medical Univ., Wroclaw, Poland;

10) Clin. of Gastroenterol, Tsaritsa Yoanna Univ. Hospital, Medical Unive. of Sofia, Sofia, Bulgaria; 11) Belarusian State Medical Univ., Dept. of Cardiol and Internal Medicine,

Div. of Gastroenterol Minsk Belarus;

12) Clin. of Gastroenterohepatology, Faculty of Medicine, Saints Cyril and Methodius University, Skopje, RN Macedonia; 13) Dept. Gastroenterol, Gr T Popa Univ. of Medicine and Pharmacy Iași, Romania

Address for correspondence: Prof .Dan L Dumitrascu, Iuliu Hatieganu University of Medicine and Pharmacy, ddumitrascu@umfcluj.ro

\section{ABSTRACT}

There is scarce information on the prevalence of irritable bowel syndrome (IBS) in East Europe. Most countries have small, local studies or studies that to our knowledge are not published in internationally available journals. This is a report from the NeurogastRO 2019 meeting held in Iași, Romania, 7-9 November 2019. During the meeting, specialists from 12 East and Central European countries presented data on IBS epidemiology in their countries. We report the stage of knowledge in each of these countries. .

Key words: Central Europe - East Europe - epidemiology - functional gastrointestinal disorders - IBS neurogastroenterology.

Abbreviations: FGID: functional gastrointestinal disorders; IBS: irritable bowel syndrome; IBS-C: IBS with predominant constipation; IBS-D: IBS with predominant diarrhea; RSN: Romanian Society of Neurogastroenterology.

\section{INTRODUCTION}

Every two years the Romanian Society of Neurogastroenterology (RSNG) organizes their international meeting of neurogastroenterology, called NeurogastRO. In November 7-9, 2019 in Iași, it was the second time that our society used this meeting in order to offer the possibility of invited lecturers from Central and East Europe to present the available data from their countries on irritable bowel syndrome (IBS) and other functional gastrointestinal disorders (FGID). In this report the main information is listed from the attending countries in alphabetic order. These data are either unpublished before or less well disseminated. Missing countries are those which did not express interest in participating in the Iași meeting. This meeting's report is aiming to add more data to the scarce information on IBS in this part of Europe [1].

\section{Albania}

There are no published data on IBS in Albania. Therefore
Galica \& Galica searched for prevalence data in the area of Korce, in East Albania in a single center pilot study, on female subjects only (oral communication). Given that females with abdominal surgery develop more frequently IBS [2], they compared also a random sample of females with at least one intervention of pelvic surgery with matched controls. Five from the 50 female subjects filled the Rome IV criteria for IBS, thus resulting in a prevalence of $10 \%$ (the main limitation is the small sample). There was no difference between the groups with pelvic surgery and no surgery; however,bloating was more frequent in surgical female patients. IBS with predominant constipation (IBS-C) was more frequent than IBS with diarrhea (IBS-D).

\section{Belarus}

This country has also no publicly available information in common references data bases on IBS. In a poster presentation, Rustamov and Derra showed data on IBS in Belarus. In this study, patients' histories of 6466 outpatients with gastrointestinal (GI) diseases who visited the gastroenterology service of Minsk Clinical Consulting Diagnostic Centre were analyzed. A number of 1698 of patients with IBS were selected. It was revealed that IBS has a prevalence of $26 \%$ from all digestive pathologies. In females, IBS is 2.5 times more common than in males. IBS occurred in all age groups with a small overrepresentation in the frequency of subtypes in the elderly.

\section{Bulgaria}

Bulgaria is another country with few data published on the epidemiology of IBS. Therefore, a group of young Bulgarian gastroenterologists initiated a study to fill in the gap (Dimitrova \& Nakov, oral communication). The study was carried out in 
the months May-August 2019. A sample of 1896 individuals ( $0.03 \%$ of the Bulgarian population) was surveyed with a 38 item questionnaire. A prevalence of $20 \%$ was found (379 patients) in the study population according to Rome IV criteria. Overall, mixed-IBS (IBS-M) was the most common subtype, accounting for $52.2 \%$ of all IBS patients in Bulgaria. IBS-D represented 32\%, IBS-C 14\% and unclassified IBS (IBS-U) $1.8 \%$. Subjects perceived themselves as being under stress and anxious.

\section{Croatia}

Croatia is one of the few countries in the region with published data on the epidemiology of IBS and reports a high prevalence of over $20 \%$ [3]. Therefore, in this meeting no new presentation of IBS epidemiology was offered. Instead, Croatia presented a comprehensive review on IBS and obesity (Hauser, oral communication). Obesity seems to be linked to IBS [4]. Visceral adipose tissue is associated with an increase risk of IBS, mainly with IBS-D. Gut microbiota is supposed to be the main link of this association.

\section{Hungary}

In Hungary there is a project aiming to identify IBS cases correctly, to build a national IBS registry and to collate information on the epidemiology of IBS in this country (Czimmer, oral communication). Using the Rome IV questionnaire compared with a sample surveyed with a Rome III questionnaire, it was found out that the prevalence of IBS in blood donors dropped from $7 \%$ to $0.7 \%$ [5]. These data have to be confirmed and completed by undergoing studies in this country.

\section{Macedonia}

From Macedonia we have a cooperative study on the prevalence of FGID in children and adolescents in the Mediterranean area [6]. According to this study, the prevalence of IBS in pediatric patients around the Mediterranean See is $4 \%$. In the Iași Meeting a study presented the differences and overlap between IBD and IBS in an audit of a colonoscopy center (Trajkovska et al, oral communication). Both IBD and IBS patients had similar demographic characteristics, but pain and weight loss were more frequent in IBD. Between IBS patients, IBS-D was more frequent.

\section{Moldova}

Moldova has no relevant data on IBS yet. Babin presented a study where stool samples were analyzed in IBS and controls (oral communication). This preliminary study showed that in IBS-D more hemolytic bacteria were found than in controls. Symptoms improved after therapy with rifaximin.

\section{Poland}

An overview of epidemiological data on FGID including IBS in the Polish population was presented by Mulak [7] at the previous NeurogastRO meeting. In a survey study conducted in 850 subjects ( $60 \%$ women), bloating was reported by $31 \%$ of the participants, dyspeptic symptoms by $23 \%$, while constipation and IBS by $13 \%$ of the subjects [8]. In another
Polish study, in which 120 female university students were included, the symptoms corresponding to IBS were observed in approximately $40 \%$ of the women [9]. The occurrence of abdominal symptoms was influenced by nutritional habits in $81.7 \%$ of the subjects and by stress in $80.8 \%$ of them [9]. Stachowska et al. [10] assessed the prevalence of abdominal pain and disturbed bowel movements in 1479 young adults (56\% women). Interestingly, the subjects were recruited among the participants of a big rock music festival in Poland and they were interviewed using an online application. The frequency of abdominal pain amounted to $19.2 \%$. Psychological distress and the use of proton pump inhibitors as well as antibiotics were associated with the increased risk of abdominal pain occurrence [10]. Recently, Poland has participated in the global Rome Foundation study shedding new light on the worldwide prevalence and burden of functional gastrointestinal disorders [11].

\section{Romania}

Romania is one of the three countries from East Europe where prevalence of IBS was investigated by an internet survey in the frame of the Rome Foundation [11]. Before this, two relevant diverging studies were available from this country and presented in Iași (Dumitrascu, oral communication). One was published only as an abstract and presented the prevalence of diagnosed IBS on the lists of family physicians [12]. On a sample of almost 25,000 subjects from the rolls of 28 general physicians (GPs,) the prevalence of the IBS diagnosis (thus, largely underestimated) was $2 \%$, with 1:1 gender ratio. In another study by Drug et al. [13] cited in the meta-analysis of Lovell and Ford [14] carried out in an urban area of East Europe,, the prevalence of IBS was $14 \%$ with a gender ratio of 1:2.

\section{Russia}

Data from Russia have been very recently presented in the Sperber study of the Rome Foundation [11]. Several more papers can be retrieved from the main data bases on IBS [15]. But epidemiological data are scarce. Therefore in Iași an oral presentation (Bordin) was submitted on FGID and data on the overlap between IBS and other FGID were reiterated. Thus, it was shown that IBS-C has a strong overlap with GERD, and functional dyspepsia [16]. More FGIDs are associated than isolated: the more conditions are associated, the more severe is IBS.

\section{Serbia}

Serbia is also making efforts to assess the burden of IBS in their country. In an oral presentation (Lukic) reported a high prevalence of IBS in urban areas (20-30\%). In an audit of a main tertiary gastroenterology center between 2017-2018, from 2308 patients, the following data on IBS were found: IBS-D was diagnosed in 117; IBS-C in 250 (the most common type) and IBS-M in 62 cases. Colon carcinoma was diagnosed in only 2 instances (IBS-C and -D); pathological findings were most common in IBS-D patients: 1 carcinoma, 7 microscopic colitis, and 8 inflammatory bowel diseases (Lukic et al, in press). Treatment is addressed to symptoms and with dietary FODMAP restrictions. 


\section{Ukraine}

In this country the estimated prevalence is $16-20 \%$ (Dorofeyev, oral communication). Post-infectious IBS represent $28.5 \%$ from total IBS cases [17]. In a previous study, Dorofoyev et al. [18] found that IBS-C was the most frequent subtype (43\%), followed by IBS-D (35\%). IBS-C was more frequent in the elderly [18]. Ukraine has a national strategy for FGID including IBS consisting of: national guidelines, reference centers, education programs, doctors' cooperation [18].

\section{DISCUSSION}

There is scarce information on the prevalence of IBS in East Europe. Most countries have small, local studies or studies that to our knowledge are not published in internationally available journals. However, the awareness on IBS is high in most of these countries and the patients benefit from management according to each nation's standards. Some East countries have societies or working groups on neurogastroenterology and a few are affiliated to the European Society of Neurogastroenterology and Motility (ESNM).

Undertaking epidemiological studies on IBS is a very challenging task [19], despite the availability of methodological guidelines [20]. Three East European countries were part of the collaborative study of the Rome Foundation on Global Survey on Functional Gastrointestinal Disorders: Romania, Poland, Russia. According to this study, general prevalence in these countries are respectively: $3.5 \%, 4.4 \%, 5.9 \%$ [11]. This study offered for the first time relevant epidemiological data based on an internet survey and the figures are lower than in many previous studies historically recorded and using other methodology (10-20\%). In the meta-analysis of Lovell and Ford 2012 [14], the pooled prevalence was in all studies $11.2 \%$, with variation from country to country (but few countries from East and Central Europe) varying from $1.1 \%$ to $45.0 \%$. In countries not involved in the Rome Foundation Global Survey, and according to data disseminated during NeurogastRO 2019, prevalence figures are higher than those reported in the Rome Foundation Global Survey.

There is a need to extend this study also in other countries, with a smaller population. Epidemiological data are the backbone for management strategies of IBS in each country. Studies on the epidemiology of IBS in each country should be based on the same methodology [21]: to be addressed to the general population, not only to in- or outpatients; to use the same questionnaire, i.e. Rome IV [22]; to use the same technique of interview (either on internet or by face to face interview). Raising funding for this project should be a task of individual countries.

The contributors of this manuscript are committed to creating a network on FGID in East Europe, using the model of the International Liaison Committee of the Rome Foundation.

\section{CONCLUSION}

This is a report from the NeurogastRO 2019 meeting held in Iași, Romania, 7-9 November2019. During the meeting, specialists from 12 East and Central European countries presented data on IBS epidemiology in their countries. We report the stage of knowledge in each of these countries. These data were either not presented before or are not visible on the main data bases.

Conflicts of interest: None to declare.

Authors' contribution: All authors delivered presentations to the NeurogastRO 2019 meeting on IBS. D.L.D. had the idea and wrote the draft; all other authors provided data, read the draft and contributed to the text and agreed the present form of the text

Acknowledgements: The authors thank Anatol V. Sikorski and Desislava Dimitrova for the support of the IBS investigations in Belarus respectively Bulgaria.

\section{REFERENCES}

1. Rusu F, Dumitrascu DL. Epidemiology of irritable bowel syndrome in the former communist countries from Eastern Europe: a systematic review. Clujul Med 2015;88:146-151. doi:10.15386/cjmed-449

2. Sperber AD, Morris CB, Greemberg L, et al. Development of abdominal pain and IBS following gynecological surgery: a prospective, controlled study. Gastroenterology 2008;134:75-84. doi:10.1053/j. gastro.2007.10.041

3. Grubić P, Jurcić D, Ebling B, et al. Irritable bowel syndrome in Croatia. Coll Antropol 2014;38:565-570.

4. Lee CG, Lee JK, Kang YS, et al. Visceral abdominal obesity is associated with an increased risk of irritable bowel syndrome. Am J Gastroenterol 2015;110:310-319. doi:10.1038/ajg.2014.422

5. Helle K, Bálint L, Inczefi O, et al. The introduction of Rome IV criteria decreased dramatically the prevalence of irritable bowel syndrome (IBS) in South-East Hungarian blood donors. Central Eur J Gastroenterol Hepatol 2017;3 Suppl 1:95.

6. Scarpato E, Kolacek S, Jojkic-Pavkov D, et al; MEAP Group. Prevalence of Functional Gastrointestinal Disorders in Children and Adolescents in the Mediterranean Region of Europe. Clin Gastroenterol Hepatol 2018;16:870-876. doi:10.1016/j.cgh.2017.11.005

7. Mulak A. Irritable bowel syndrome and functional gastrointestinal disorders in Poland. NeurogastrRO 2017 - Meeting of the Romanian Society of Neurogastroenterology with Rome IV Regional Central-East European Meeting, Iasi, Romania, 16-18 March 2017. Proceedings; Drug V, Dumitrascu DL. (eds.); Bologna; FilodritoEditore, 2017;9-12.

8. Ziółkowski BA, Pacholec A, Kudlicka M, Ehrmann A, Muszyński J. Prevalence of abdominal symptoms in the Polish population. Gastroenterol Rev 2012;7:20-25. doi:10.5114/pg.2012.27218

9. Niemyjska A, Ukleja A, Ławiński M. Evaluation of irritable bowel syndrome symptoms among Warsaw University students. Pol Przeg Chirurg 2015;87:252-259.

10. Stachowska E, Maciejewska D, Ryterska K, et al. Abdominal Pain and Disturbed Bowel Movements are Frequent among Young People. A Population Based Study in Young Participants of the Woodstock Rock Festival in Poland. J Gastrointestin Liver Dis 2018;27:379-383. doi:10.15403/jgld.2014.1121.274.pol

11. Sperber AD, Bangdiwala SI, Drossman DA, et al. Worldwide Prevalence and Burden of Functional Gastrointestinal Disorders, Results of Rome Foundation Global Study. Gastroenterology 2020 Apr 12. doi:10.1053/j. gastro.2020.04.014 
12. Dumitrascu DL, Nedelcu L, Balan A, Nechifor D. IBS in Romania (abstr.). World Congress of Gastroenterology, Montreal 2005.

13. Drug VL, Costea F, Ciochină AD, et al. Functional digestive disorders and the relationship with psychiatric diseases. Rev Med Chir Soc Med Nat Iasi. 2002;107(2):307-310

14. Lovell RM, Ford AC. Global prevalence of and risk factors for irritable bowel syndrome: a meta-analysis. Clin Gastroenterol Hepatol 2012;10:712-721.e4. doi:10.1016/j.cgh.2012.02.029

15. Davydov DM, Shahabi L, Naliboff B. Cardiovascular phenotyping for personalized lifestyle treatments of chronic abdominal pain in Irritable Bowel Syndrome: A randomized pilot study. Neurogastroenterol Motil 2019;31:e13710. doi:10.1111/nmo.13710

16. Lazebnik LB, Masharova AA, Bordin DS, et al. Multicentre Study „Epidemiology of Gastroesophageal Reflux Disease in Russia”(MEGRE): First Results. Eksp Klin Gastroenterol 2009;(6):412.

17. Tkach SM, Mirzabaeva NM. The post-infection of the irritable bowel: recent recommendations of the Rome Foundation Working team. Modern Gastro 2019;1:93-101. doi:10.30978/MG-2019-1-93
18. Dorofeyev AE, Kiriyan EA, Vasilenko IV, Rassokhina OA, Elin AF Clinical, endoscopical and morphological efficacy of mesalasine in patients with irritable bowel syndrome. Clin Exp Gasroenterol 2011;4:141-153. doi:10.2147/CEG.S18381

19. Sperber A, Dumitrascu D, Fukudo S, et al. The global prevalence of IBS in adults remains elusive due to the heterogeneity of studies: a Rome Foundation working team literature review. Gut 2016;66:1075-1082. doi:10.1136/gutjnl-2015-311240

20. Boeckxstaens GE, Drug V, Dumitrascu D, et al; COST Action BM1106 GENIEUR members. Phenotyping of subjects for large scale studies on patients with IBS. Neurogastroenterol Motil 2016;28:1134-1147. doi:10.1111/nmo.12886

21. Sperber AD, Gwee KA, Hungin AP, et al.Conducting multinational, cross-cultural research in the functional gastrointestinal disorders: issues and recommendations. A Rome Foundation working team report. Aliment Pharmacol Ther 2014;40:1094-1102. doi:10.1111/apt.12942

22. Whitehead W, Drossman DA, Chang L, Kellow J, Chey WD, Tack J. Rome IV diagnostic questionnaires and tables for investigators and clinicians. First edition. Rome Foundation 2017. 